$$
\begin{array}{r}
\text { EMBARALHAN } \\
\text { NORDESTES: PRODUÇ } \\
\text { DE SUJEITOS, TEMPC } \\
\text { ESPAÇOS NAS NARRATI } \\
\text { E PERFORMANCES } \\
\text { JOÃO DO CR }
\end{array}
$$




\section{EMBARALHANDO NORDESTES: PRODUÇÃO DE SUJEITOS, TEMPOS E ESPAÇOS NAS NARRATIVAS E PERFORMANCES DE JOÃO DO CRATO}

\section{ROBERTO MARQUES}

UNIVERSIDADE REGIONAL DO CARIRI, PPGS/UECE 
EMBARALHANDO NORDESTES: PRODUÇÃO DE SUJEITOS, TEMPOS E ESPAÇOS NAS NARRATIVAS E PERFORMANCES DE JOÃO DO CRATO ${ }^{12}$

\title{
Resumo
}

Esse artigo problematiza a textualização da região do Cariri (CE) a partir das narrativas e performances do artista e militante João do Crato. Ao tempo que lança luzes sobre os deslocamentos de tempos e espaços que produzem novas formas de compor lugares e sujeitos no interior do Ceará, tenta-se indicar perspectivas metodológicas de usos das narrativas em antropologia. A partir do palco, demonstra-se como João do Crato cria um lugar para si como diferença e um lugar de diferença habitável por seu público e companheiros e companheiras de militância política.

Palavras-chave: Cariri, cultura popular, etnobiografia.

SHUFFLING NORTHEASTS: PRODUCTION OF SUBJECTS, TIMES AND SPACES IN THE NARRATIVES AND PERFORMANCES OF JOÃO DO CRATO

\begin{abstract}
This article problematizes the textualization of the region of $\mathrm{Ca}$ riri (CE) fromnarratives and performances of the artist and activist João do Crato. While we shed light on the displacements of times and spaces that produce new forms of composing places and subjects in the interior of Ceará, we try to indicate methodological perspectives of uses of the narratives in anthropology. From the stage, we show how João do Crato creates a place for himself as difference and a place of difference habitable by his audience and companions of political militancy.
\end{abstract}

Keywords: Cariri, popular culture, ethnobiography. 


\section{BARAJANDO NORDESTES: PRODUCCIÓN DE SUJETOS, TIEMPOS Y ESPACIOS EN LAS NARRATIVAS Y PERFORMAN- CES DE JOÃO DO CRATO}

\section{Resumen}

Este artículo problematiza la textualización de la región de Cariri (CE) a partir de las narrativas y performances del artista y activista João do Crato. Al tiempo que lanza luces sobre los desplazamientos de tiempos y espacios que producen nuevas formas de componer lugares y sujetos en el interior de Ceará, el artículo intenta indicar perspectivas metodológicas para los usos de las narrativas en antropología. Desde el escenario, se demuestra cómo João do Crato crea un lugar para sí como "diferencia” y un lugar de diferencia habitable por su público y por sus compañeros y compañeras de militancia política.

Palabras clave: Cariri, cultura popular, etnobiografía.

Endereço do autor para correspondência: Rua Ana Loiola de Alencar, 813. Bairro: Pimenta Crato. Ceará. Cep: 63113-424.

enleio@yahoo.com.br 
INTRODUÇÃO: ESPELHAMENTOS ENTRE O RURAL E O URBANO EM LUGARES DE TRADIÇÃO

Esse texto esboça um projeto maior que busca aproximar a potente tradição de estudos biográficos em antropologia, a produção sobre narrativas e performances e os usos de fontes imagéticas e sonoras.

Retomarei aqui um conjunto de entrevistas coletadas entre os anos 1990 e 2016 na região ao sul do Ceará chamada Cariri (Marques 2004; 2008). No limite desse texto, pontuarei momentos em que o cantor e ativista João do Crato descreve algumas apresentações ocorridas ao longo de seus 40 anos de carreira. A partir dessas narrativas, tento articular as noções de espacialidades e performances, avaliando seu alcance e potência na redescrição criativa de lugares e sujeitos. Como pretendo demonstrar, na etnobiografia de João evidencia-se o lugar privilegiado que o palco ocupa nos deslocamentos que produz e inspira.

O nome de João do Crato está associado à geração do rock cearense a partir do final da década de 1970. Tendo se mudado para a capital cearense para "servir o exército", passa a ter contato com as bandas Perfume Azul e Xá de Flor, acompanhado por artistas como Lúcio Ricardo, Mona Gadelha e Sigbert Franklin. De volta à cidade de Crato, reencontra, entre outros, seus conterrâneos Abidoral Jamacaru; Luís Carlos Salatiel; Rosemberg Cariry; Manel de Jardim e Cleivan Paiva. Jovens que entre as décadas de 1970 e 1980 organizaram mais de uma dezena de festivais da canção, algumas mostras de artes ao ar livre, além de lançarem filmes, livros e promoverem shows que buscavam modernizar a linguagem da cultura jovem local de então (Campos, 1986; Regis, 2003; Marques, 2004, Dias, 2014).
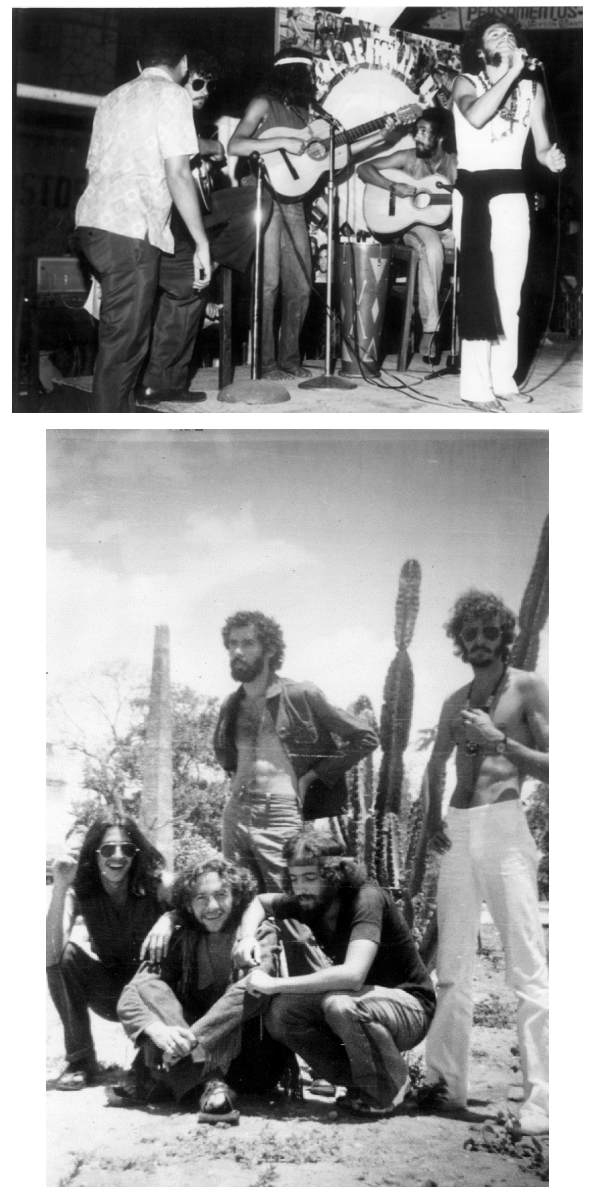

Meu interesse por João e o grupo de artistas próximo a ele se deu pela possibilidade de refletir, a partir de sua geração, sobre a sedução pelo "de fora", por determinado cosmopolitismo como destino (Marques 2004; 2008). Cosmopolitismo aparentemente inesperado para uma cidade no interior do Ceará. 
Pode-se dizer que o Cariri se apresenta e é reapresentado ao mundo como um lugar de tradição. Sua história está marcada por personagens emblemáticas como Padre Cícero, liderança religiosa e política na Velha República (Della Cava, 2014; Schwarcz, 2012); pela po- ética de Patativa do Assaré e a saga da Tipografia São Francisco (Slater 1982; Melo 2010) referência na edição de folhetos de cordéis no Brasil, bem como pelo canto de Luiz Gonzaga, um dos principais agentes da visibilização de um Nordeste migrante ${ }^{3}$.

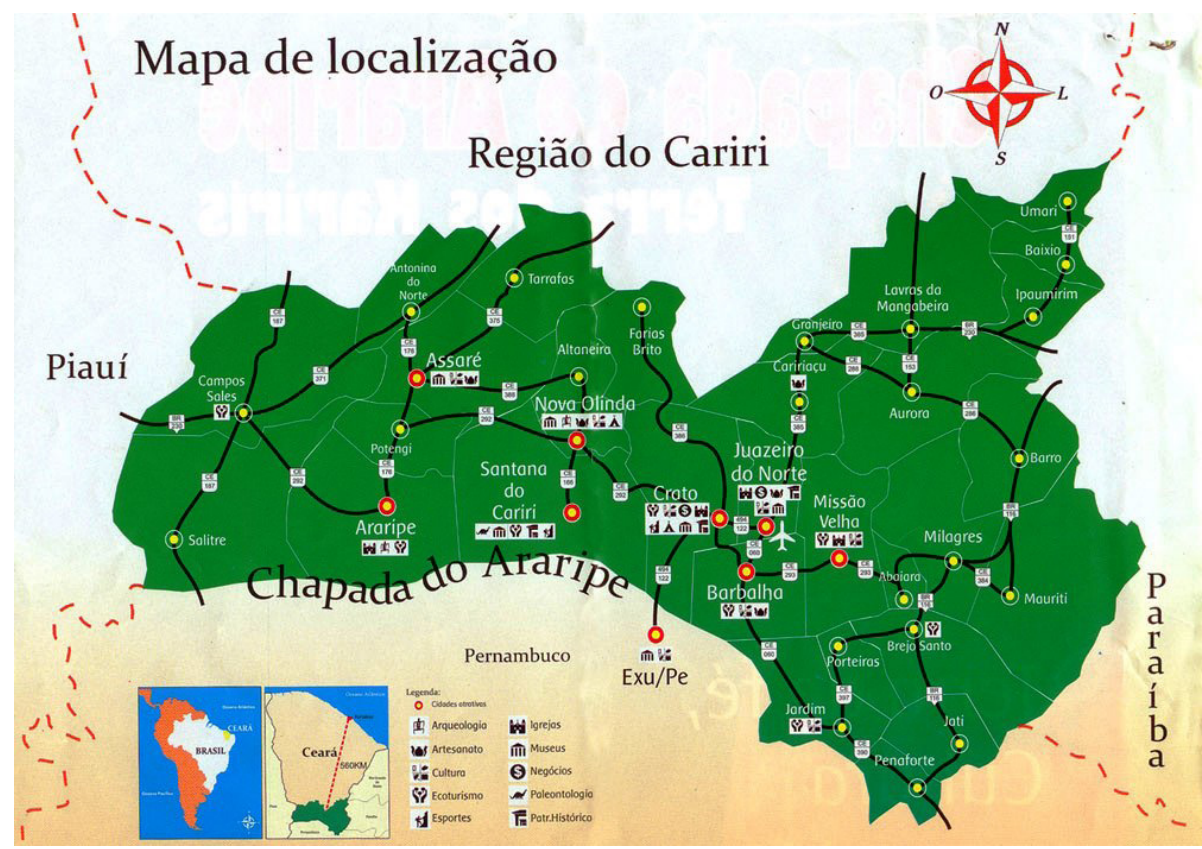

Quando falamos da região do Cariri falamos, portanto, de uma experiência incomum de tensões contínuas entre as narrativas que dão forma às ideias de rural e urbano. Lugar cujo crescimento econômico possibilitou, nas décadas de 1950 e seguintes, o deslocamento das camadas médias locais. Fluxo de pessoas e tecnologias que fez convergir vivências que pareciam se estender para além das fronteiras do mundo rural, presentificando-as em cidades de médio e grande porte, como, por exemplo: o gosto de "comer com coentro", da música de Gilberto Gil (1969); o leiteiro vendendo leite mun- gido de porta em porta; o desejo de comer baião de dois em pleno centro urbano.

O deslocamento e os jogos narrativos que constroem o "lá" e o "aqui" como uma oposição entre o rural e o urbano $^{4}$, ao mesmo tempo desmascaram a insuficiente implantação de direitos e deveres afeitos às ideias de cidadania característica da sociedade brasileira nas últimas décadas (Duarte 2013).

Essa tensão, presentificada em polos opositores diversos como "rural - urbano"; "Nordeste - Sudeste"; "interior - capital”, demanda atenção contínua 
às formas inusitadas de recepção das experiências ocorridas em metrópoles e cidades de grande porte nessas outras localidades, tomadas como rurais, periféricas ou interioranas. Tais vivências são reconhecidas a um só tempo como "diferença" em oposição à experiência local e como ideal, naquilo que Velho (1978) chamou de "ideologia do bem-estar".

Nesse trabalho específico, as vivências da geração de artistas e produtores culturais da qual João do Crato faz parte estão marcadas pela vontade de liberdade e irreverência, característica da recepção da contracultura no Brasil, e pelas narrativas que consolidaram figuras de identidade local e particularidade ao modo de insígnias reapresentadas de forma constante por personagens localizados espacialmente a partir de uma suposta identidade regional (Marques 2008). Em nome dessa identidade regional, pessoas e trajetórias são tipificadas como representantes de uma cultura que lhes antecederia, na forma de clichês estereotípicos (Albuquerque Jr. 1999).

Como pretendo demonstrar, João do Crato e sua geração lidam com essas forças de forma particularmente criativa. Utilizarei aqui, portanto, a literatura sobre narrativas e agência a fim de pensar tais espacialidades e suas formas de subjetivação não mais como cenário fixo, subjetivado ao modo "fora-dentro", mas como dado da própria experiência de produzir culturas e identificações, sendo elas mesmas passíveis de modificação e instrumentalização de performances, reiteradas ou não sob a forma de atos no mundo (Gupta \&
Fergunson 2000; Gonçaves 2008).

Para Rapport (2000):

"Narrativas podem ser entendidas como estórias que as pessoas contam sobre si mesmas e seus mundos. O canal ("medium") de seus contos narrativos pode variar (de palavras a imagens; de gestos a comportamentos rotineiros), o que é invariante é a característica das narrativas em propagar uma sequência significativa através do tempo e espaço (...). Em um mundo em movimento, as narrativas proveem ao ser em deslocamento ${ }^{5}$ - seja antropólogo ou informante- um lugar cognitivo para habitar e construir sentido. Um lugar para continuar a ser” (p. 74, tradução nossa).

Ao definirem os verbetes "Agente" e "Agência", Rapport e Overing (2000) chamam a atenção para o papel da criatividade/criação na produção de mundos.

"Já que o que é vivido agora é resultado de atos imaginativos de criação de mundos ocorridos no passado, dependente de práticas individuais contínuas para se institucionalizarem, inevitavelmente atos imaginativos no presente levarão a novos futuros possíveis; no processo de criar um novo mundo, mundos pré-existentes são inexoravelmente apropriados” (p. 05, tradução nossa).

Aproximando esse postulado à ideia de narrativas em antropologia, é importante frisar que o ato imaginativo não é um cálculo racional. É expressão narrativa articuladora de mundos. Dessa forma, interessa-nos a forma como essa articulação narrativa provê um lu- 
gar para o sujeito, uma "self-creation", conforme Crapanzano (1982), a partir de um enquadramento de mundos ordenados.

As narrativas serão aqui, portanto, tomadas, a exemplo do que nos ensinou Rapport (1992; 2000) como um campo etnográfico, um "lá" que alia um espaço, não no sentido de lugar (um "estar lá”), mas no sentido cognitivo do termo, capaz de aliar imagem e imaginação (Caiuby Novaes, 2008), de maneira muito mais evocativa que informativa (Crapanzano 1982:14).

João do Crato parece nos introduzir essa possibilidade ao descrever sua performance no palco:

"O repertório da banda de rock [Xá de Flor] era um repertório muito em cima do que acontecia na época no rock internacional. Tinha uma influência muito forte do Yes, do Genesis, sabe... Quem é no Brasil que fazia isso? Os Mutantes, né? Os Mutantes tinham uma coisa universal, mas ao mesmo tempo tinham uma coisa muito regional da coisa brasileira, né? A Tropicália! Os Mutantes tinha isso. Mas como eu era o vocalista de frente [da Xá de Flor], que fazia toda a performance, eu usava muito esses elementos.

Talvez fosse isso que chocasse um pouco. Sempre as apresentações da Xá de Flor eram muito irreverentes por causa dessa minha performance no palco, e o que atraía de certa forma também as pessoas. O que diferenciava das outras bandas era minha presença no palco, que tinha uma coisa de guerreiro indígena, de negritude também. Eu sempre fui muito ligado a essa coisa dos ritos indígenas e afro-brasileiros. Eu gosto da umbanda e adoro ir aos terreiros de macumba pra ver os tambores tocarem e aqueles caboclos dançando e esse é um elemento muito presente na minha formação artística, na minha performance como cantor. Então eu acho que isso chamava muito atenção na Xá de Flor: eu mexer com esses elementos. De estar cantando rock progressivo e ter uma postura de caboclinho, de um maracatu, de uma coisa assim que eu tinha bebido nas fontes aqui do regionalismo" (João do Crato, Entrevista 26 de Abril de 1999).

\section{NARRATIVAS DE NORDESTES PO- LIFÔNICOS: CONTRACULTURA NO CARIRI}

Conheci João no final dos anos 1990. Naqueles anos, muito jovem, eu costumava frequentar bares alternativos em Crato, cidade que recentemente me adotara como morador. No bairro São Miguel, após a linha do trem, o bar Xá de Flor ${ }^{6}$, o Arranha-céu e o Lobo's bar confluíam um público animado e criativo, em torno de cachaças temperadas, boa música e certo ar urbano e irreverente. Por esses bares, acostumei-me a ver personagens histriônicos cuja presença, longos cabelos cacheados e roupas particularmente coloridas modificavam o ambiente a seu redor.

João do Crato não era frequente nesses bares. No entanto, em um restaurante bem próximo dali, assisti a uma de suas apresentações pela primeira vez. Sua postura atlética, cabelos louros, pele bronzeada e voz de tenor contras- 
tavam com seus gestos sinuosos e sua calça de lycra rosa bebê boca de sino. Não há como descrever tal ambiguidade sem que o leitor tente categorizar João a partir da gramática da diversidade em vigor nesse nosso início do século XXI.

Para dimensionar o inaudito daquela imagem para alguém como eu, recém saído da capital do Estado para morar no "interior", vale lembrar que a performance tomava lugar no final dos anos 1990, em um pequeno palco de um restaurante em uma cidade que contabilizava àquela época não mais que 95.000 habitantes $^{7}$. É inútil portanto significar sua presença no palco a partir de termos como rural, urbano, homocultura, kitsch. Como tentarei desenvolver adiante, os contrastes ambientados nos palcos daquela e de outras apresentações de João são particularmente misteriosos.

Digamos por ora que naquela noite aprendi que João pertencia a uma geração de artistas com franca inspiração no movimento de contracultura e no entre lugares do sertão do Ceará e do cosmopolitismo da década de 1970. Essa geração instituiu para si, e para a cidade talvez, uma nova estética e estilística de existência.

Passaram-se alguns anos até que eu realizasse com ele a primeira entrevista.

João devia me categorizar como um jovem professor, vindo da capital do Estado, identificado com o mundo acadêmico e urbano. Àquela época, eu ia constantemente à casa de uma família de amigos em comum no bairro São Miguel, bairro onde João mora até hoje. Isso, aliado ao fato de eu frequentar bares alternativos da cidade, o que rendeu contatos e referências em comum, possivelmente fizera com que João atendesse meu pedido de realizar aquela primeira entrevista.

Para Crapanzano (1982):

"A história de vida e a autobiografia (...) são essencialmente constituidoras do self: momentos fixados no tempo pela palavra, no processo dialético de autocriação ("self-creation"). Elas requerem, como tal, a mediação de um Outro (...) O Outro inclui não simplesmente o indivíduo concreto ao lado mas todos aqueles por ele representados simbolicamente. (...) A história de vida é um produto do desejo do autor por reconhecimento desse $\mathrm{Ou}$ tro essencialmente complexo. Não é apenas informativa. É evocativa também" (9-10, tradução nossa).

Dessa forma, pacientemente, enquanto eu conversava sobre contracultura no Cariri, João me apresentava os grupos, oposições e tensões existentes na região, a fim de contextualizar para um recém-chegado os acontecimentos expressos em sua narrativa.

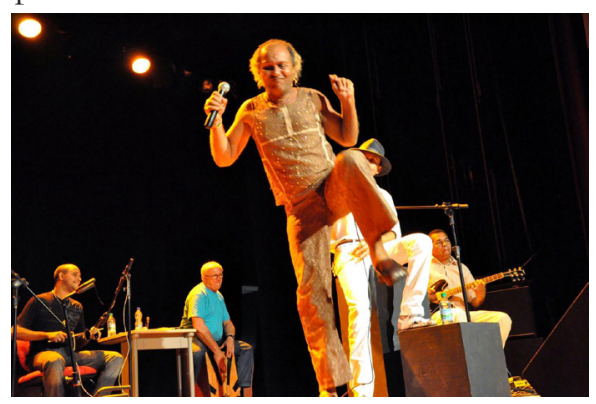

Imagem 04: João do Crato Fotografia: Wilson Bernardo. Disponível em: http:// olharesdocariri.blogspot.com.br/. Acesso em: 28/05/2014. 
"Acho que [durante os anos 1970], a luta aqui setorizada no Crato era contra isso. Contra a coisa que mais nos oprimia, que era essa questão do coronelismo" - Ensinava-me. Para João, a tradição colonial dos senhores de engenho se expressa(va) de forma multifacetada. Não apenas nas relações de desigualdade de gênero, raça e classe social, mas também na estética das produções teatrais e musicais da primeira escola de artes da cidade do Crato, a Sociedade de Cultura Artística do Crato (SCAC); na relação de intelectuais e famílias locais com a cultura popular e seus mestres. "As mães do folclore" ironizou João. Em sua fala, tais atributos da cidade eram então contrapostos à mudança realizada por sua geração:

"Aqui na nossa região nós já temos um grupo de pessoas novas, contemporâneas, que já estão com o pensamento ligado no que está acontecendo no universo todo, uma coisa de modernidade até, mas que a gente ainda não conseguiu se impor perante essas coisas tradicionais".

João narra sua geração como um "a gente". O faz a partir de uma polarização simples entre tradicional e moderno. Nessa polarização, considera-se um aliado do moderno, um agente da modernidade. Consolida sua narrativa a partir da descrição de eventos capazes de estabelecer uma oposição entre uma moral tradicional-local-linear-"careta" em contraste a atitudes alinhadas a experimentação-modernidade-cosmopolitismo. Efetivamente essa oposição é construída a partir da citação de momentos de embate entre essas duas vozes na cidade. Fala assim, por exemplo, da utilização do espaço realizada por jovens de sua geração da Praça da Sé, praça principal da cidade em frente à Igreja Matriz:

"A malucada tomou conta da Praça da Sé! As pessoas que vinham de fora armavam barracas (...) chegou a ter quinze barracas armadas naqueles jardins, de maluco, de gente acampando, tomando pico. De certa forma era uma coisa muito louca, que agredia aquelas famílias tradicionais, tá entendendo? E por incrível que pareça...é realmente engraçado essas coisas...os filhos desse pessoal era um pessoal que depois estava dentro do movimento... Pra matar os pais do coração! Então a Praça da Sé tinha esse estigma. Quem frequentava a Praça da Sé... já [se] sabia: fumava maconha, era liberado demais. E tinha uma coisa que... que foi muito liberal mesmo! O pessoal fumava mesmo liberadamente! (...) E a gente tinha a turma da Praça da Sé que andava todo mundo junto, em bloco, pra subir pra nascente, pra subir pra cascata. (...) Tinha, às vezes, o pessoal que achincalhava, vaiava, jogava pedra na gente: - "Lá vêm os cabeludos!" - Porque na época, já estava todo mundo de cabelão já!".

Em Marques (2004), argumento que a existência dessa geração é atestada também pela narração/construção de um novo modo de deambulação na cidade. Apartados das instituições responsáveis pela produção política e estética do Cariri então, cabia a esses jovens artistas instituírem um novo modo de narrar a cidade, novos mapas de deslocamento, consolidando uma nova geografia. 
No presente texto, pensarei algo distinto. Considero que a produção de um Cariri cosmopolita e contemporâneo se deu não apenas pelo tráfico de imagens, ideais e simbolismos, mas também pela constituição de uma narrativa dentro e fora dos palcos. Justifica-se, portanto, o experimento etnobiográfico (Gonçalves et al 2013).

\section{CENA 01: BORRANDO ROCK CE- ARENSE E CULTURA POPULAR NA FESTA DE EXPOSIÇÃO AGROPECU- ÁRIA}

Pensarei aqui a forma como João consolida sua fala sobre o Cariri. Uma fala que é definitivamente geracional, mas que é também dependente de sua agência e posição social.

Rapport (1992) nos ensina que a textualização da interação contínua entre as personagens que descreve em seus textos, a atenção devotada a suas palavras e seus gestos, é a forma encontrada de materializar a diversidade biográfica desses personagens. A reiteração das trocas públicas, verbais e outras funcionando como um verniz das intenções particulares privadas. A partir disso, incita:

\section{"Registrar as formas rotineiras de relações culturais sem descrever os indivíduos particulares que regu- larmente usaram-nas em interação seria destituir as formas dos pro- pósitos e processos pelos quais tais práticas foram habitualmente trazi- das à vida" (196, tradução nossa).}

Seguindo a premissa de Rapport, reportar-me-ei à forma invulgar pela qual João do Crato narra o conflito en- tre tradição e modernidade no Cariri a partir de uma relação distinta da interação cotidiana: suas narrativas sobre suas performances no palco. Ao longo das entrevistas, a construção narrativa dessas cenas nos chega como criação de um espaço prenhe de devir.

"Nessas minhas vindas de férias [de Fortaleza] eu vim com o Batista Sena, que era o líder da banda (...). Era quem realmente compunha as canções da banda Xá de Flor. E a gente fez um show na fundação Padre Ibiapina, nesse auditório que hoje é o auditório da [Universidade Regional do Cariri] URCA. (...) O nome do show era Show Calha. Juntou-se Pachelli Jamacaru, juntou-se todo mundo. Pachelli já era do movimento da Massafeira ${ }^{8}$, né? Tinha ido para o Rio gravar o disco com Ednardo e coisa e tal. (...) A partir daí, foi quando eu comecei a me entrosar com o pessoal daqui. (...) Depois, em 80 parece, a gente veio fazer um show na exposição do Crato. Foi uma viagem maravilhosa! Veio todo mundo de trem!"

A descrição do show da banda Xá de Flor por João é bastante reveladora:

"Esse show na exposição foi maravilhoso (...). Quase não aconteciam shows na exposição. Os shows que aconteciam eram shows folclóricos, alguma coisa artística da região mesmo. Não era essa megaexposição que fazem hoje! Era uma coisa muito mais autêntica, que você via os grupos folclóricos, os grandes astros, as grandes estrelas eram os grupos folclóricos. As pessoas iam para ver o reisado, pra ver as lapinhas, para ver os emboladores, os cantadores de coco, as rodas de 
coco. Eram as estrelas da Exposição. E a gente entrou nessa, pra fazer esse show porque a gent...nós... eu era da cidade! Né? E se abriu esse espaço pra gente".

Seguindo as trilhas metodológicas de Rapport, ressalto as múltiplas temporalidades articuladas nessa narrativa de autocriação ("self-creation"). Aqui se articulam ao mesmo tempo: as [grandes] apresentações na Exposição no tempo presente em que ocorreu a entrevista, o ano de 1999; a centralidade da Exposição Agropecuária na descrição da cidade de Crato $^{9}$ e da região do Cariri e o tempo imemorial dos artistas populares.

Desenvolvamos cada um desses tempos:

No final de 1990, artistas como Elba Ramalho, Luiz Melodia, e outros se apresentavam em grandes palcos, sem a venda de ingresso para um público que vinha de várias cidades e capitais do Nordeste ${ }^{10}$. Em sua narrativa sobre a Exposição Agropecuária de Crato, João borra as temporalidades desses espetáculos gratuitos com o evento tal como ocorrido nos anos 1980, quando ele efetivamente se apresentara com a banda Xá de Flor. Mistura assim a experiência contemporânea dos grandes shows ao longo da década de 1990 e sua importância para o fluxo de pessoas para a cidade do Crato com o evento de proporções locais da década de 1980.

Em sua sobreposição de tempos, descreve emboladores, cantadores e reisado como "as grandes estrelas da exposição". Ora, provavelmente tais artistas dispunham dos mesmos recursos para apresentar-se na Expocrato que dispunham na feira livre da cidade onde cantavam então, lugar que centralizava semanalmente a compra e venda de produtos alimentícios para grande parte da região do Cariri ${ }^{11}$. Em seu projeto narrativo de cidade, no entanto, faz-se necessário que João aproxime grandes artistas no palco e os emboladores, colocando-se como mediador desse entre lugares.

Isso fica claro com a continuidade da descrição por João:

"João do Crato: $\mathrm{Na}$ época se abriu esse espaço pra gente...

Roberto Marques: Só pra vocês?

JC: Pra gente.

RM: Só pra vocês?

JC: Não sei se teve outra coisa, outro, outra...mas se tiver acontecido... acho que quem fazia mesmo a festa era Luís Gonzaga. Na época, grandes shows, fora os grupos folclóricos, eram o Luís Gonzaga, o pessoal mais ligado ao regionalismo mesmo, aquela coisa do forró autêntico... O Trio Nordestino. Era esse pessoal mesmo. E a gente era uma banda de rock! Mas como eu era da cidade...findou-se que se abriu esse espaço".

João segue descrevendo o show:

"E a gente fez esse show que foi muito bom na exposição. Eu lembro que era muito deficiente, né, o som não era legal, sabe? Tudo muito precário, mas a gente fez, né? Mas foi muito bom! A partir daí a gente...logo depois a banda teve uma ascensão, a gente começou a fazer muitos shows em Fortaleza. De certa forma, na época, a televisão comentava mais os trabalhos dos artistas. Hoje em dia não, ela é 
mais fechada (...) e as pessoas daqui viam, na época só tinha a TV Verdes Mares que vinha pra cá, mas se falava na banda Xá de Flor, falava-se de João do Crato e foi quando as pessoas começaram a ver que eu existia, que eu estava fazendo um trabalho lá [em Fortaleza] e tal".

A criação de João como artista fica assim marcada [em sua narrativa] não só por temporalidades, mas por espacialidades distintas. Como os artistas populares, o Trio Nordestino e Luís Gonzaga, João pode se apresentar na exposição: ele é da cidade. Ao mesmo tempo, sua impertinência a esse lugar, ou outra forma de pertinência, é expressa na frase: "Fora os grupos folclóricos (...) era o pessoal mais ligado ao regionalismo mesmo (...). E a gente era uma banda de rock. Mas como eu era da cidade... findou-se que se abriu esse espaço." Frases adiante, como que repetindo o sonho de Caetano Veloso (1967) em "Alegria, alegria'12" João se revela à sua cidade pela televisão: "Foi quando as pessoas começaram a ver que eu existia”. Dessa alternância de tempos e espaços, João encontra a possibilidade de enraizar-se ${ }^{13}$ como pessoa e como artista. Justificar-se como cantor de fora e como João do Crato.

\section{A PRODUÇÃO NARRATIVA DE LU- GARES PARA SI}

Rapport chama a atenção para como a narrativa de deslocamento da antropologia, acaba por exigir de seus interlocutores uma suposta permanência, "the complaisance of immobility" (2000:73). É necessário, nos ensina Ra- pport, para a antropologia e seus colaboradores, encontrar um lugar cognitivo para se estabelecer em um mundo em deslocamento. Nesse sentido, a fala de João sobre seu lugar no Cariri, criado a partir do palco é bastante marcada pelo sentido de impertinência comum à sua geração. Ao mesmo tempo, sua autocriação fora dali, a partir de veículos de distribuição não presenciais, vem conjugar sentidos de sua biografia pessoal.

"JC: As pessoas daqui já estavam de certa forma produzindo um movimento cultural com a cara da modernidade da época: O Grupo de Amigos do Crato, o pessoal do grupo Matulão, os Festivais da Canção do Crato (...). Então, para o tamanho da região, era uma coisa fantástica! (...)

RM: Você foi contemporâneo dessas pessoas todas...

JC: $\mathrm{Na}$ realidade eu era contemporâneo, mas eu não era tão envolvido com o movimento porque esse movimento era mais centralizado no Parque Municipal, no centro da cidade, e eu sempre morei mais na periferia.

RM: [O bairro de] São Miguel era periferia?

JC: Era super periferia! Totalmente isolado! Talvez [o movimento] fosse até um pouco fechado e eu não conseguisse [me aproximar] e talvez não fosse não! Talvez eu é que fosse fechado...Só assistia porque eu não tinha ...é ...assumido essa coisa da arte mesmo dentro de mim...Eu tinha tudo dentro, na cabeça, mas tudo ainda muito confuso. Só vim descobrir mesmo e tornar concreto quando eu saí daqui e fui pra Fortaleza. E foi quando todo mundo foi 
embora: Abidoral [Jamacaru] foi embora, Cleivan [Paiva] foi embora, Rosemberg [Cariri] foi embora" (Entrevista 199914).

Treze anos após essa entrevista, em conversa com a equipe do Projeto Percursos Urbanos, do Centro Cultural Banco do Brasil, em Juazeiro do Norte, João fala mais uma vez sobre sua ida a Fortaleza ${ }^{15}$ :

"Quando eu migrei para Fortaleza para fazer o serviço militar. Eu não queria fazer aqui. Eu não queria fazer de jeito nenhum, na verdade. (...) Fui pra lá pra conseguir a dispensa e fiquei” (2012).

Em sua entrevista para mim, em 1999, João já falava sobre o tema, sublinhando o sentido de deslocamento/ falta de lugar para si, tema revisitado na entrevista ocorrida mais de uma década depois:

"Quando eu saí daqui, na realidade eu fui pra Fortaleza, eu não fui aventurando nada. Eu queria era fugir da coisa do serviço militar porque era obrigatório aqui e eu não queria servir porque ...eu era uma pessoa muito tímida, era muito isolado, eu era uma pessoa que vivia muito só... eu tive uma adolescência muito pra dentro, sabe? Por eu ser diferente, eu já via outras coisas e eu achava que... eu não sei, talvez fosse a confusão que eu tinha dentro da minha cabeça de não saber o que é que eu queria" (1999).

Retomando o tema de sua relação com os outros jovens artistas da geração de 1980, João fala:

"Eu poderia muito bem ter participado ativamente da coisa, porque os meus amigos que, por incrível que pareça os meus contemporâneos da época, tá entendendo? Eles já estavam totalmente... fazendo o que eu não tinha coragem de fazer, que era fumar maconha, que era... era...porque você sabe que nos anos 70 foi que tudo se abriu! Tudo era muito fechado, então nos anos 70 com Woodstock a coisa de fumar maconha foi que foi liberada, até a questão do homossexualismo que eu lembro que eu tinha, os meus amigos, as pessoas daqui, que poderiam ser os meus amigos, que vieram a ser depois que eu voltei de Fortaleza nos anos 80, na época eles já tinham uma liberdade que eu não tinha coragem de ter. Eu também tinha um certo medo daquilo. Mesmo porque eu vinha de uma família que tinha dois irmãos mais velhos que eu, altamente machistas, e eu de certa forma desde pequeno era diferente. Desde pequeno que eu cantava (...) Eu não ia caçar de baladeira, eu não ia jogar bola com os outros, e cheguei até a jogar, porque [estalo com as mãos] porque eu sentia que se eu não fosse, seria muito mais difícil, não é? Então eu cheguei a jogar bola, cheguei a fazer coisas que os meninos da minha época faziam, mas porque eu já sentia uma pressão muito forte da, da...do meio em que eu vivia, porque eu era diferente" (1999).

Apenas conjugando em suas narrativas as ideias de mundo urbano, contracultura, liberdade e irreverência em embate às forças que o impediam de se revelar como diferença, João consegue levar a cabo sua autocriação ("self creation") e o sentido de enraizamento ("sense of groundedness") no local onde nasceu. 
Rapport chama atenção para a importância da repetição e reiteração da posição na criação de um lugar cognitivo para si que se possa chamar de um lar. Dessa forma, a biografia de João revela um deslocamento típico, um percurso geracional ao mesmo tempo típico e único, como nos ensina Crapanzano (1982). Nessa experiência de enraizamento, em que João parece ocupar um lugar tão afeito a cultura popular, tão tipicamente caririense e ao mesmo tempo tão impertinente ao que se espera desse lugar, é que o palco aparece como formação de compromisso, um lugar a um só tempo materialmente imanente e cognitivamente deslocado do Cariri. João parece compor isso em suas próprias palavras em uma experiência de verdade autobiográfica (Crapanzano 1982).

"Eu lembro que quando criança eu escutei uma vez acho que David Bowie, eu via Tom Jones, Elvis Presley e eu me imaginava um dia em um palco daqueles, Madison Square Garden, um palco tipo... aqueles palcos, mas depois passou. Fui vendo que era uma coisa muito distante e que eu tinha que romper um bocado de coisa e eu não sei se eu teria coragem de meter as caras nesse sonho, não. Ai vi que não que o grande palco da vida é aqui também. Que de repente você tá cantando em cima de um caminhão desses, como eu já cantei tanto em comícios nos caminhões e trios elétricos e coisa assim, que é o grande palco, tá entendendo? E que você pode fazer, transformar o ... a carroceria de um caminhão no Madison Square Garden, é só querer, e o público é o mesmo, tá entendendo?
E tanto faz você estar cantando lá no Japão como estar cantando aqui no meio da feira. E que você tem que cantar é onde você tá mesmo e transformar o seu ambiente. Sabe, eu já tenho consciência disso (1999)".

\section{CENAS 02 E 03: BORRANDO CUL- TURA POPULAR E PERFORMATIVI- DADE DE GÊNERO NO FESTIVAL DA REDE GLOBO E NA FESTA DO PAU DA BANDEIRA DE SANTO ANTÔ- NIO, EM BARBALHA}

Ao longo da entrevista, a ideia de performance como momento apartado do tempo parece compor a narrativa de João. Dessa forma, nas próximas descrições de suas atuações no palco da tradicional festa de Santo Antônio, em Barbalha e no festival regional Canta Nordeste, João parece estar bastante consciente das vantagens de tensionar os limites do possível no palco para compor sua identidade como personagem e como artista.

"É preciso muita coragem, viu, pra você subir num palco, como eu subi em Barbalha, em um sábado na festa de encerramento da festa de Santo Antônio em que devia ter umas 10.000 pessoas, 20.000 pessoas ou mais. Ali você subir, como eu subi, com uma roupa totalmente nua! Subi só com uma malha de tarrafa, daquelas furadinhas, sabe? E com um calçãozinho de retalhos de lamê dourado e um fraque de lamê. O povo não entendeu nada! Os palcos de Barbalha já estavam sendo dominados pelas bandas de forró $^{16}$, né, e eu subia e quebrava tudo aquilo! (1999)". 
Em outro momento, João descreve sua apresentação no Festival Canta Nordeste:

"Durante o Canta Nordeste, em 1993, foi a maior polêmica do mundo! Porque eu fiz uma canção dedicada a Dona Cícera [do Barro Cru $]^{17}$, que tinha morrido e eu fiz uma música. Um dia eu me levantei, peguei o papel e "praaa" escrevi. Parecia uma coisa mediúnica mesmo, uma canção pra ela, que transformei em um samba enredo pra escola de samba do meu bairro. (...) Todo mundo elogiou - "Hum, que coisa linda, que música maravilhosa! Que samba maravilhoso! _". Ai eu digo: "-Vou escrever esse no [Festival] Canta Nordeste" - E escrevi, e o samba arrebentou! Entre as 500 canções inscritas, a maior nota da triagem foi a do samba. De repente me ligaram e disseram: "Olha, sua música ficou entre as doze finalistas do Canta Nordeste" -. E ai, o que foi que eu fiz? Eu digo: - "Eu quero cantar essa música como se fosse um boneco de Dona Cícera!" - Ai falei com Giovani, que é um amigo meu, artista plástico, maravilhoso, e ele pegou um bonequinho de Dona Cícera e trans...me transformou num boneco! Meu corpo era todo pintado, né? $\mathrm{E}$ a minha roupa era um guerreiro! Um embaixador do reisado! Era uma coroa, de papel machê uma espada de papel machê, o corpo todo pintado como se fosse um boneco de barro e um saiote de um palmo de papelão também, todo pintado. E pra fechar mais ainda, botei só um tapa-sexo por baixo!"

Se é no tensionamento dos limites do palco que João promove sua auto-cria- ção narrativa, ele parece estar consciente ao longo de sua criação narrativa que sua posição serve também para desnudar os limites impostos a sua carreira. Apontando a reatividade a sua experiência criativa no palco.

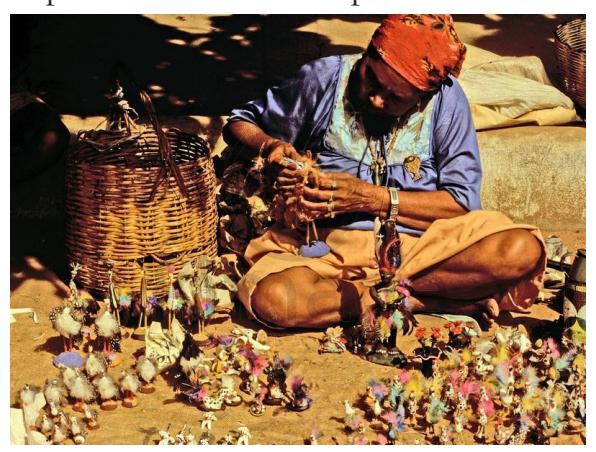

Imagem 05: Dona Cícera do Barro Cru vendendo esculturas em Crato. Disponível em: www.kimage.com.br. Acesso em: $31 / 05 / 2014$.

"Foi um desaforo para a caretice da Rede Globo de Fortaleza. Eu fiquei escondido, embaixo do palco, sem ninguém me ver. Quando me chamaram, que eu subi, acho que se eles pudessem ter mandado cortar pra não filmar... mas como não podiam... eles tiveram que acatar. Só que depois... eles filmaram pra passar o tape, né? E o tape eles editaram todinho! Foi a única coisa que eles editaram! Porque eu fiz! Eu subi naquele palco pra ser irreverente! Eles não sabiam quem era Dona Cícera do Barro Cru, eles não sabiam que roupa era aquela minha, eles achavam que eu estava era apelando! Que eu queria era me mostrar! E foi uma comédia, uma polêmica, tremeu o palco! Eu fui agredido no palco pelos dois apresentadores. (...) Eles ficaram apavorados quando me viram. E a Rede Globo toda! Eles nunca es- 
peravam que um concorrente do festival fosse fazer aquilo! Porque eles têm que ter o controle! Eles querem que vá todo mundo com o cabelinho amarrado, com gel, e de um coletezinho de retalho! $\mathrm{Pa}$ dronizam todo mundo! E eu fui já pra quebrar aquilo!" (1999).

Curiosamente, lembro-me de ter assistido ao festival pela televisão em 1993. A descrição de João não poderia ser mais exata. Todos os demais concorrentes se apresentaram com uma roupa de retalhos e, após flashes de imagem de João do Crato, sua apresentação fora cortada do tape que foi ao ar. Em sua narração, chama atenção a interpretação de João desse momento em palco como um choque entre gramáticas: “-Eles não sabiam quem era Dona Cícera do Barro Cru, eles não sabiam que roupa era aquela minha, eles achavam que eu estava apelando! -”. Se sua posição é sustentada pela importância da arte de Dona Cícera do Barro Cru, importância não reconhecida pelos organizadores do festival, algumas frases adiante, João revela outra condição de possibilidade para sua performance: a expressão dos artistas da década de 1960 e 1970 nos festivais universitários da época.

"Porque eu acho que é isso mesmo. Festival é pra quebrar, como Caetano [Veloso] quebrou numa época, lá dos anos 70! Como Os Mutantes quebraram! Com aquele discurso que Caetano Veloso fez! Um desabafo(...)! Eu não fui pra subir pra ganhar festival! Fui pra mostrar aquilo ali! Pra fazer o protesto! Pelo descaso com a arte popular! Por eles não saberem nem o que é que eu representava ali!" (1999).

João segue comentando a repercussão de sua participação:

"Aqui no Crato repercutiu...foi bom porque repercutiu. Demais! Não pra mim, mas pras pessoas foi muito polêmico! Porque disseram que eu estava nu, que eu tinha arreganhado a bunda pro Júri, coisa que não aconteceu...E que eu tinha sido desclassificado por causa da irreverência. Não era pra ter feito aquilo!" (1999).

Por fim, João cita a repercussão junto a outros artistas cearenses:

"O próprio Fidélis fez um comentário, disse que festival tanto pode ser a glória do artista como pode ser a desgraça, pro João foi a desgraça! Ele soterrou a carreira artística dele, sabe.

Lá em Fortaleza, virou fofoca. Lembro que seis meses depois, ainda se comentava nos bares esse meu escândalo no Canta Nordeste. Os próprios artistas, meus amigos, faziam fofocas nos bares. Eu lembro Dilson Pinheiro me imitava, fazia minha caricatura! Eu acho ótimo! Mesmo que fosse de uma maneira meio carregada de crítica e preconceito, eu não me importava não. Eu acho ótimo que faça! Ainda hoje eu sou um artista que quando se fala meu nome em Fortaleza, as pessoas tem medo. Eu sei o quanto as pessoas tem preconceito comigo, sabe, porque eles sabem que quando eu chego num palco, eu chego é pra chegar... Eu não chego pra ficar bonitinho ali e sair não". 


\section{CONSIDERAÇÕES FINAIS}

É notório o uso que João faz das imagens que consolidaram ao longo do século XX a ideia de Cariri como região. Não apenas de forma reativa, a partir da imaginação de um polo tradicional-local-linear-"careta", mas de forma argumentativa. Incorporando a partir dessas imagens valores e identificação. Por exemplo:

"RM: Qual era o motivo das pessoas [mochileiros e artistas dos anos 1970 e 1980] irem e virem [ao Cariri] assim?

JC: Acredito que as pessoas daqui já estavam de certa forma produzindo um movimento cultural com a cara da modernidade da época. Aqui é uma região (...) historicamente muito forte, Bárbara de Alencar, teve o Movimento da Confederação do Equador, que de certa forma propiciou que tivesse uma geração subsequente muito ligada a isso (...) tentando resistir (...) manter esse movimento vivo aqui na cidade" (1999).

\section{Em outro momento:}

"Eu acho que minha formação foi toda em cima da arte popular porque (...) aqui, quando a gente era criança no Cariri, no dia de feira era uma festa. (...) Por que a feira era tudo isso aqui, aqui onde nós estamos, a feira se estendia por isso aqui tudo. Então essa praça Siqueira Campos era um foco de grupos artísticos(...), geralmente em duas ou três praças estava rolando reisado, na outra rolava embolador. Era uma festa para os olhos!" (1999).

A importância da cultura popular é um fator comum na narrativa de vários ou- tros artistas dessa geração com quem tivemos contato: na música de Abidoral Jamacaru; na interpretação teatral e musical de Luís Carlos Salatiel; na fotografia e cinema de Bola Bantim. É um dado bastante perceptível também ao longo da filmografia de Rosemberg Cariry $(1985 ; 1993 ; 2001)$.

Possivelmente, nenhum deles a tenha apreendido de forma tão particular quanto João do Crato. A composição de um guerreiro de Dona Cícera do Barro Cru, de tapa-sexo, sendo editado e censurado em um tape da Rede Globo é uma apropriação criativa, um "mal uso da língua" (Bakhtin 1993) que tomam forma e ganham integração em uma estória contínua (Rapport 1992) na autocriação de João como artista, nesse espaço de presença-ausência do palco, e em sua(s) narrativa(s).

Retomando Crapanzano (1982), poderíamos dizer que a narrativa de João é ao mesmo tempo "particular e estereotipada" (passin, 80-82). Nesse sentido, o que permitiria que essa apropriação incomum perdurasse como narrativa no e a partir do Cariri ao longo dos últimos 40 anos da vivência pública de João do Crato?

Ao longo de vinte anos de convívio com João, sua trajetória particular como militante identificado aos grupos e comunidades onde se produz arte popular fica bastante evidente. João acompanhou, por exemplo, os penitentes de Barbalha em apresentações públicas por todo o Brasil; intermedeia atualmente a presença e registro de uma equipe de pesquisadores de várias universidades nacionais junto ao 
grupo de Mulheres do Coco, no bairro Batateiras. Alia-se a isso sua participação aos movimentos sociais, como atesta na entrevista concedida à equipe local do Projeto Percursos Urbanos do CCBNB.

"Entrei de cara nos movimentos sociais quando voltei [de Fortaleza]. Tinha uma identidade muito grande. E tinha um grupo aqui que estava se formando, hoje uma ONG, que foi a pioneira. Trabalha com movimentos sociais, com agricultura familiar. Passei a ter um vínculo muito grande com a zona rural; a participar de reuniões de associações comunitárias, sindicatos rurais. Participei muito ativamente do processo [de ocupação] do Caldeirão. Quando as famílias invadiram e foram expulsas do Caldeirão, nós as alojamos todas no parque de exposições aqui do Crato. E demos assistência todos os dias, animando também, até que fosse liberada a terra onde eles estão estabelecidos agora: o assentamento 10 de Abril. Invasões Urbanas. O conjunto Novo Crato, que hoje está estabelecido, também foi uma invasão de terra que a gente participou ativamente. (...) Eu estava lá cadastrando as coisas, demarcando as casinhas lá debaixo do sol quente. Isso foi uma vitória também. Teve todo esse envolvimento do processo social, das lutas sociais, das lutas ambientais. A gente sempre brigou muito pela preservação do sítio Fundão, para que fossem estabelecidas novas áreas de proteção dos riachos e das matas do Cafundó. Também tem a luta pela questão da caça indiscriminada na floresta. Enfim, teve toda uma luta ambiental e social muito grande. E acho que isso culminou nesses projetos culturais de agora que a gente acompanha. Como o Carrapato Cultural, o grupo Urucongo, como o grupo lá do Arajara do mestre Gilberto e do Chico Ceará, que é um grupo de maculelê, samba de roda e danças afro-brasileiras. Está culminando nesse grande leque que a gente pode chamar de cinturão cultural do Cariri, que começa lá em Barbalha, na zona rural, e vem beirando o pé da serra e vem se constituindo nesse grande trabalho gratificante. Estar vendo essa juventude, essa criançada se interessando por essas manifestações. É muito difícil você lutar contra uma cultura de massa que é fulminante, que chega e tem força, tem a mídia toda...” (2012).

João foi também convidado a falar diversas vezes sobre sua trajetória como artista nos centros culturais da região, notadamente o CCBNB, SESC-Crato e SESC-Juazeiro do Norte, compondo a partir de sua trajetória, uma narrativa sobre cultura no Cariri.

Retomando, portanto, a relação entre expressões sonoras e a construção política de identidades, poderíamos dizer que a invenção de um personagem por João do Crato, que compõe sua "diferença" a um só tempo como artista ("self-criation") e como gramática do Cariri (na narrativa sobre sua apresentação no Canta Nordeste, acima) impõe uma reflexão sobre uma consolidação concomitante do social e do individual, a partir de narrativas que são sobre ele e sobre o Cariri, em um experimento etnobiográfico expresso sobre o palco e também fora dele. 


\section{NOTAS}

${ }^{1}$ Versão revista e ampliada de trabalho apresentado na 29a Reunião Brasileira de Antropologia, realizada entre os dias 03 e 06 de agosto de 2014, Natal/RN.

${ }^{2}$ Pesquisa de Pós-doutorado, vinculado ao IFCS/UFRJ, financiada pelo CNPq. Essa pesquisa conta também com apoio da Pró-reitoria de Pesquisa e Pós-Graduação da Universidade Regional do Cariri, mediante a Chamada Pública PRPGP 03/2013 Apoio À Pesquisa E Produção Científica 2013/2014.

${ }^{3} \mathrm{~A}$ importância desses personagens é confirmada pelo alcance das obras de Della Cava (1970; 2014); Carvalho (1988); Granjeiro (2002; 2013); Lima (1985); Camurça (1994); Barros (1988); Slater (1982; 1984; 1986); Vieira (2000); Gonçalves (2007); Melo (2010).

${ }^{4} \mathrm{Um}$ excelente exemplo dessa forma de figuração é a obra de Luiz Gonzaga, como bem demonstram Vieira, 2000 e Marques, 2008b.

${ }^{5}$ No original "Narratives provides for the world-traveller- whether anthropologist or informant- a place cognitively to reside and make sense" (p. 74)

${ }^{6}$ Batizado em homenagem à banda de Fortaleza em que João do Crato cantava.

${ }^{7}$ Dados do Censo de IBGE/ 1996.

${ }^{8}$ No ano de 1979 , cerca de quarenta músicos, intérpretes, produtores e arranjadores que participaram da movimentação cultural em torno da Massafeira Livre viajaram para o Rio de Janeiro para gravar o álbum, que foi lançado pela gravadora CBS (hoje Sony Music). O evento, ocorrido no Theatro José de Alencar, marcou a primeira apresentação de Patativa do Assaré na capital cearense. A recitação de "Senhor Doutor" pelo poeta popular foi a única faixa gravada durante o evento incluída no álbum duplo lançado em 1980. O cantor e compositor Ednardo fez a direção artística, direção de produção e direção de estúdio do álbum Massafeira. A co-produção foi assinada por Augusto Pontes. A coordenação musical ficou a cargo de Rodger Rogério, Petrúcio Maia e Stélio Valle. Sobre o tema, ver: Ednardo (2010).

${ }^{9}$ A Exposição Agropecuária de Crato é um evento anual ocorrido desde 1944. Além do comércio de produtos agropecuários por grande, pequenos e médios produtores do Nordeste, possui programação musical e de lazer destinada a diferentes públicos.

${ }^{10} \mathrm{Em}$ distinção a esses grandes eventos gratuitos, a partir de meados de 2000 , produtores de eventos passaram a concorrer em licitação para utilizar um espaço exclusivamente destinado a shows, com venda de ingressos unitários ou em "pacotes", para todos os dias do evento, de camarotes, de bebidas e de comida, entre outras atrações, sobre isso ver Marques (2015).

${ }^{11}$ Sobre isso, Almeida Júnior, radialista e filho de radialista na cidade de Crato, conta uma curiosa anedota: $\mathrm{O}$ sistema de alto-falantes utilizado nas primeiras exposições agropecuárias da cidade eram cedidos pela diocese de Crato. Certa ocasião, Zé Gonzaga, irmão do cantor e compositor Luíz Gonzaga, fizera um show em que cantava, tocava e contava anedotas. O tom picante das anedotas não foi bem aceito pela igreja, que recolheu todas as radiadoras do parque de exposição, tendo os artistas nesse ano e no ano seguinte se apresentado sem nenhum equipamento de som.

${ }^{12} \mathrm{Na}$ música emblemática de Caetano Veloso, o autor fala dos sonhos nascidos com os novos produtos e meios de comunicação na década de 1960 e 70: Cardinales, Bardots, Jornais, Coca-cola, fazendo com o que, ao invés de pensar em casamento, ele sonhe "em cantar na televisão", para assim "seguir vivendo". 
${ }^{13}$ Para Rapport (2000:75): "sense of groudedness and home".

${ }^{14}$ A partir da observação metodológica de Nigel Rapport, o texto tenta explicitar os lugares narrativos produzidos por João em suas entrevistas. A partir de agora, essas entrevistas serão identificadas apenas pelo ano em que ocorreram, entre parênteses, ao final de cada fala.

${ }^{15}$ Agradeço aos estudantes de jornalismo da Universidade Federal do Cariri (UFCA) Alana Maria Soares e Antônio Rodrigues, assim como ao Professor Tiago Coutinho Parente, o acesso à entrevista concedida por João do Crato.

${ }^{16}$ As bandas de forró eletrônico no Ceará e restante do Nordeste começam a atuar nos anos 1990. Sobre isso, ver Marques (2015).

${ }^{17}$ Dona Cícera do Barro Cru foi ceramista nascida em Crato. Suas peças não iam ao forno, justifica-se por ai a alcunha pela qual ficou conhecida. Suas peças ocupam importante lugar em museus e coleções de arte popular.

\section{REFERÊNCIAS}

Albuquerque Júnior, D. M. 1999. A invenção do Nordeste e outras artes. Recife: FJN, Masangana/ São Paulo: Cortez.

Bakhtin, M.. 1993. Questões de literatura e de estética: a teoria do romance. São Paulo: Hucitec.

Barros, L. O. C. 1988. A Terra da mãe de Deus: Um estudo do movimento religioso de Juazeiro do Norte. Rio de Janeiro: Francisco Alves; Brasília: INL.

Bauman, R. 2009. A Poética do mercado público: gritos de vendedores no México e em Cuba. Ilha Revista de Antropologia 11(1) (2):17-39.

Bauman, R., e C. L. Briggs. 2006. Poética e performance como perspectivas críticas sobre a linguagem e a vida social. Ilha Revista de Antropologia 8(1)(2):185-229.

Campos, M. 1986. Colonialismo cultural interno: o caso Nordeste. Fortaleza: Banco do Nordeste do Brasil.

Camurça, M. 1994. Marretas, molambos e rabelistas. A Revolta de 1914 no Juazeiro. São Paulo: Maltes.

Caiuby Novaes, S. 2008. Imagem, magia e imaginação: desafios ao texto antropológico. Mana. 14(2): 455-475. Rio de Janeiro.

Cardoso, V. Z. 2007. Narrar o mundo: estórias do "povo da rua" e a narração do imprevisível. Mana. 13(2): 317-345. Rio de Janeiro.

Carlson, M. 2010. Performance: Uma Introdução crítica. Belo Horizonte: UFMG.

Carvalho, G. 1998. Madeira Matriæ: São Paulo: Annablume.

Crapanzano, V. 1982. Portrait of a Moroccan. Chicago: Univesity of Chicago Press.

. 1984. Life-histories. American Anthropologist 86(4): 953-960.

Della Cava, R. 1970. Miracle at Joaseiro. New York: Columbia University Press. 1914. Milagre em Joaseiro. $3^{a}$ ed. São Paulo: Companhia das Letras.

Dias, C. R. 2014. Tradição versus modernidade: recepção do projeto identitário do ICC, in Da flor da terra aos guerreiros cariris: representações e identidades do Cariri cearense (1855- 1980). Dissertação, Mestrado em História, Universidade Federal de Campina Grande, Campina Grande.

Duarte, L. F. D. 2013. Desejo e diferença Á guisa de prefácio, in: As novas guerras sexuais: Diferença, poder religioso e identidade LGBT no Brasil. Organizado por M. Natividade \& L. Oliveira. Rio de Janeiro: Garamond. 
Ednardo (org.). 2010. Massafeira- 30 anos - Som, Imagem, Movimento, Gente. Fortaleza: Edições Musicais.

Gonçalves, M. A. 2007. Cordel híbrido, contemporâneo e cosmopolita. Textos escolbidos de cultura e arte populares. 4(1):21-38. Rio de Janeiro.

Gonçalves, M. A. 2008. O Real imaginado: Etnografia, cinema e surrealismo em Jean Rouch. Rio de Janeiro: 7Letras.

Gonçalves, M. A., R. Marques, e V. Z. Cardoso.. 2013. Etnobiografia: subjetividade e etnografia. Rio de Janeiro: 7Letras.

Grangeiro, C. R. P. 2002. O Discurso religioso na literatura de cordel de Juazeiro do Norte. Crato: A Província.

2013. Discurso politico no folheto de cordel. São Paulo: Annablume.

Gupta, A., e J. Ferguson. 2000. Mais além da 'cultura': espaço, identidade e política da diferença, in $O$ espaço da diferença. Organizado por A. A. Arantes. Campinas: Papirus.

Langdon, E. J. 2006. Performance e sua diversidade como paradigma analítico: A contribuição da abordagem de Bauman e Briggs. Ilha Revista de Antropologia 8(1) (2):162- 183.

Lima, F. A. S. 1985. Conto popular e comunidade narrativa. Rio de Janeiro: FUNARTE/ Instituto Nacional do Folclore.

Marques, R. 2004. Contracultura, tradição e oralidade: (Re)inventando o sertão nordestino na década de 70. São Paulo: Annablume.

2008a. Seja moderno, seja marginal: engenhos e artimanhas da contracultura no Cariri. Sociedade e cultura 1(2):191-198.

2008b. Nordestinidade, música e desenraizamento ou eram os tropicalistas nordestinos?, in Leituras sobre música popular: reflexões sobre sonoridade e cultura. Organizado por E. Giumbelli, Emerson, J. C. Valladão,
S. C. Naves, A. Neder . Rio de Janeiro: 7 Letras.

2015. Cariri eletrônico: paisagens sonoras no nordeste. São Paulo: Intermeios.

Melo, R. A. 2010. Arcanos do verso: trajetórias da literatura de cordel. Rio de Janeiro: 7Letras. Rapport, N. 1992. From affect to analysis. The biography of an interaction in a English village, in Anthropology and autobiography. Organizado por J. Okely \&, H. Callaway. New York: Routledge. 1997. Transcendet individual. Towards a literary and liberal anthropology. New York: Routledge.

2000. The narrative as fieldwork technique. Processual ethnography for a world in motion, in Constructing the field: ethnographic fieldwork in the contemporary world. Editado por V. Amit. New York: Routledge.

Rapport, N., e J. Overing. 2000. Agent and Agency, in Social and cultural Anthropology: the key concepts. London: Routledge.

2000. Individuality, in Social and cultural Anthropology: the key concepts. London: Routledge.

Regis, I. L. M. 2003. Lu₹, câmera, sertão. Bravura e fé na cinematografia de Rosemberg Cariry 1986- 1996. 2003. Dissertação, Mestrado em História, Universidade Federal do Ceará, Fortaleza.

Runyan, W. M. 2014. Life histories in anthropology: Another view. American $A n$ thropologist. 88(1): 181-183. <Disponível em: www.jstor.org/stable/679192>.

Schwarcz, L. M. 2012. População e sociedade, in A abertura para o mundo: 18891930. História do Brasil Nação - vol. 3. Coordenado por L. M. Schwacz. Madrid/Rio de Janeiro: Fundaciòn Mapfre/ Objetiva.

Seeger, A. 1997. Por que os índios suya cantam para suas irmãs?, in Arte e sociedade. 
Ensaios de sociologia da arte. Organizado por G. Velho. Rio de Janeiro: Zahar.

Seeger, A. 1991. Styles of musical etnography, in Comparative musicology and anthropology of music. Essays on the history of ethnomusicology. Editado por B. Nettl, \&, P. V. Bohlman. Chicago: The University of Chicago Press. Slater, C.. 1982. Stories on a string. The Brazilian Litertura de Cordel. California: University of California Press.

1984. A Vida no barbante. A Literatura de Cordel no Brasil. Rio de Janeiro: Civilização Brasileira.

1986. Trail of miracles. Stories from a Pilgrimage in Northeast Brazil. California: University of California Press, 1986.

Soares, A. M., e T. C. Parente. 2012. Percursos urbanos: "O Crato do João" como reflexão sobre memória e contracultura. Anais do IV Encontro Universitário da UFC no Cariri.

Velho, G. 1978. A utopia urbana: um estudo de antropologia social. Rio de Janeiro: Zahar.

Vieira, S. 2000. O sertão em movimento: a dinâmica da produção cultural. São Paulo: Annablume.

FILMOGRAFIA:

Cariry, R. O Caldeirão de Santa Cruz do Deserto. Cariri Filmes. Fortaleza, Ceará. 1985.

A Saga do guerreiro alumioso. Cariri Filmes. Fortaleza-Ceará, 1993.

Juazeiro. A Nova Jerusalém. Cariri Filmes. Fortaleza-Ceará, 2001.

ENTREVISTAS:

João do Crato; Roberto Marques. Realizada em 26/04/1999.

João do Crato; Alana Maria Soares; Antônio Rodrigues; Tiago Coutinho Parente. Realizada em 2012a.
João do Crato. Transcrição da apresentação no Projeto Narrativas ao redor do fogo. Realizado em 2012b.

\section{MÚSICAS:}

Caetano Veloso. Alegria, alegria. Caetano Veloso. Rio de Janeiro, PHILIPS, 1967.

Gilberto Gil. Cultura e civilização. Gal Costa. Rio de Janeiro, PHILIPS, 1969.

Recebido em 15/02/2017

Aprovado em 18/03/2017 